\title{
Efficacy and safety of chemopreventive agents on colorectal cancer incidence and mortality: systematic review and network meta-analysis
}

This article was published in the following Dove Press journal:

Clinical Epidemiology

\author{
Sajesh K Veettil,' Peerawat \\ Jinatongthai, ${ }^{2,3}$ Surakit \\ Nathisuwan, ${ }^{4}$ Nattawat \\ Teerawattanapong, ${ }^{2,3}$ Siew \\ Mooi Ching, ${ }^{5,6}$ Kean Ghee \\ Lim, ${ }^{7}$ Surasak Saokaew, ${ }^{3,8-10}$ \\ Pochamana Phisalprapa," \\ Christopher M Reid, ${ }^{12,13}$ Nathorn \\ Chaiyakunapruk $3,9,14,15$
}

'Department of Pharmacy Practice, School of Pharmacy, International Medical University, Kuala Lumpur, Malaysia; ${ }^{2}$ Division of Pharmacy Practice, Faculty of Pharmaceutical Sciences, Ubon Ratchathani University, Ubon Ratchathani, Thailand; 'School of Pharmacy, Monash University Malaysia, Subang Jaya, Malaysia; ${ }^{4}$ Clinical Pharmacy Division, Department of Pharmacy, Faculty of Pharmacy,

Mahidol University, Bangkok, Thailand; ${ }^{5}$ Department of Family Medicine, Faculty of Medicine and Health Sciences, Universiti Putra Malaysia, Serdang, Malaysia; ${ }^{\circ}$ Malaysian Research Institute on Ageing, Universiti Putra Malaysia, Serdang, Malaysia; ${ }^{7} \mathrm{Clinical}$ Universiti Putra Malaysia, Serdang, Malaysia; ${ }^{7} \mathrm{Cl}$ School, Department of Surgery, International
Medical University, Seremban, Malaysia; ${ }^{8}$ Center of Health Outcomes Research and Therapeutic Safety (Cohorts), School of Pharmaceutical Sciences, University of Phayao, Phayao, Thailand; ' Center of Pharmaceutical Outcomes Research, Department of Pharmacy Practice, Faculty of Pharmaceutical or Pharmacy Practice, Faculty of Pharmaceutical Sciences, Naresuan University, Phitsanulok, Thailand Unit or Excellece on Herba Mediche, School of Pharmaceutical Sciences, University of Phayao, Phayao, Thailand; "'Division of Ambulatory Medicine, Department of Medicine, Faculty of Medicine Siriraj Hospital, Mahidol University, Bangkok, Thailand; ${ }^{12}$ School of Epidemiology and Preventive Medicine, Monash University, Melbourne, VIC, Australia;

${ }_{13}^{13}$ chool of Public Health, Curtin University, Perth WA, Australia; ${ }^{14}$ School of Pharmacy, University of Wisconsin, Madison, WI, USA; ${ }^{15}$ Asian Centre for Evidence Synthesis in Population, Implementation and Clinical Outcomes (PICO), Health and Wellbeing Cluster, Global Asia in the 2 Ist Century (GA2I) Platform, Monash University Malaysia, Subang Jaya, Malaysia

Correspondence: Nathorn Chaiyakunapruk Faculty of Pharmaceutical Sciences, Naresuan University, Phitsanulok, 65000, Thailand

Tel +66840094460

Fax +66 5596373 I

Email nathorn.chaiyakunapruk@monash.edu

Surakit Nathisuwan

Department of Pharmacy, Faculty of Pharmacy, Mahidol University, 447 Sri-ayutthaya Road, Rajthewi, Bangkok, 10400, Thailand

Tel/fax +6626448694

Email surakit.nat@mahidol.ac.th
Background: Various interventions have been tested as primary prevention of colorectal cancers (CRC), but comprehensive evidence comparing them is absent. We examined the effects of various chemopreventive agents (CPAs) on CRC incidence and mortality.

Methods: We did a network meta-analysis based on a systematic review of randomized controlled trials (RCTs) that compared at least one CPA (aspirin, antioxidants, folic acid, vitamin B6, vitamin B12, calcium, vitamin D, alone or in combination) to placebo or other CPA in persons without history of CRC. Several databases were searched from inception up to March 2017. Primary outcomes were early and long-term CRC incidence and mortality.

Results: Twenty-one RCTs comprising 281,063 participants, 9 RCTS comprising 160,101 participants, and 7 RCTs comprising 24,001 participants were included in the network meta-analysis for early risk of CRC incidence, long-term risk of CRC incidence and mortality, respectively. For early CRC incidence, no CPAs were found to be effective. For long-term CRC incidence and mortality, aspirin was the only intervention that showed protective effects with potential dose-dependent effects (risk ratio [RR], 0.74 [95\% CI, 0.57-0.97] for high-dose [ $\geq 325 \mathrm{mg} /$ day] and RR, 0.81 [95\% CI, $0.67-0.98]$ for very-low-dose [ $\leq 100 \mathrm{mg} /$ day]). Similar trend was found for mortality (RR, 0.43 [95\% CI, 0.23-0.81] for low-dose [ $>100-325 \mathrm{mg} /$ day] and RR, 0.65 [95\% CI, 0.45-0.94] for verylow-dose). However, in net clinical benefit analysis, when combining risk estimates on mortality from CRC, cardiovascular disease, and pooled risk estimates of major gastrointestinal bleeding, low-dose aspirin provided the highest net survival gain (\%) of 1.736 [95\% CI, 1.010-2.434].

Conclusion: Aspirin at the dose range of $75-325 \mathrm{mg} /$ day is a safe and effective primary prevention for long-term CRC among people at average risk. None of the other CPAs were found to be effective. There may potentially be differential effects among various doses of aspirin that needs further investigation.

Keywords: colorectal cancer, primary chemoprevention, chemopreventive agents, aspirin, network meta-analysis, net clinical benefit analysis

\section{Plain language summary}

Aspirin (75-325 mg/day) is a safe and effective intervention to prevent colorectal cancer among people at average risk. The effect may be dose and time-dependent. No other tested interventions were found to be effective. Net clinical benefit analysis combining mortality from CRC, cardiovascular disease, and bleeding indicated that low-dose aspirin ( $>100-325 \mathrm{mg} /$ day) provided the highest net survival gain. For patients with low risk of bleeding, low-dose aspirin may slightly be more attractive due to a larger reduction in CRC mortality and the best net clinical benefit. For patients at high risk of bleeding, very-low-dose aspirin ( $\leq 100 \mathrm{mg} /$ day) may be more appropriate due to its best safety profile especially in cases of GI bleeding. There may potentially be differential effects among various doses of aspirin that needs further investigation. 


\section{Introduction}

Colorectal cancer (CRC) is the fourth leading cause of death due to cancer worldwide. ${ }^{1}$ The burden of CRC on society with respect to mortality, morbidity, and costs is enormous. Therefore, prevention of CRC is an important public health objective. A number of pharmacological interventions have been investigated in randomized controlled trials $(\mathrm{RCTs})^{2-32}$ as chemopreventive agents (CPAs) for CRC in persons at average risk (those without personal or family history of colorectal neoplasia or conditions such as inflammatory bowel disease or hereditary colorectal cancer syndrome ${ }^{33}$ with variable results. A recent meta-analysis of RCTs by the United States Preventive Services Task Force (USPSTF) suggested that aspirin taken for several years could be effective in reducing long-term incidence and mortality due to CRC. ${ }^{34,35}$ However, the relative efficacy and safety of aspirin at different doses has not been investigated yet. Moreover, comprehensive evidence comparing different CPAs including aspirin is still lacking. Previous reviews and meta-analyses ${ }^{27,34,36-40}$ have focused only on pair-wise comparison of various CPAs.

Hence, we performed a systematic review and network meta-analysis (NMA) to determine the relative efficacy and safety of various CPAs on CRC incidence and mortality in persons at average risk. Since aspirin is recommended by USPSTF for both prevention of cardiovascular disease and colorectal cancer, ${ }^{35}$ therefore interested to evaluate the overall impact of various doses of aspirin on CRC mortality, cardiovascular (CV) mortality, and major gastrointestinal (GI) bleeding events through net clinical benefit analysis. This information may uniquely offer an evaluation to the multidimensional impact of a single intervention, which is aspirin in this case.

\section{Methods}

\section{Protocol and registration}

This study was performed as part of a systematic review which has been previously registered (PROSPERO CRD42015025849) ${ }^{41}$ and was reported according to the Preferred Reporting Items for Systematic Reviews and Meta-Analyses (PRISMA) extension statement for NMA. ${ }^{42}$

\section{Search strategy and study selection}

We identified relevant studies by a systematic search of Medline, Embase, Cochrane Central Register of Controlled Trials, CINAHL Plus, and International Pharmaceutical Abstracts until March 2017. In addition, we searched the clinical trial registry (www.clinicaltrials.gov) and published systematic reviews. The search was restricted to studies published from 2008 onwards because studies published up to 2007 could be identified from the published high-quality systematic reviews. ${ }^{36,37,39}$ Studies included were RCTs and long-term follow-up of RCTs, which reported the efficacy of any CPAs for the primary prevention of CRC in individuals at average risk. ${ }^{33}$ Supplement 1 details the search strategies.

\section{Type of interventions}

Candidate CPAs were aspirin, any antioxidants (vitamins A, $\mathrm{C}$ and $\mathrm{E}$, beta-carotene and selenium alone or in different combinations), folic acid, vitamin B6, vitamin B12, calcium and vitamin $\mathrm{D}$ (alone or in combination). The interventions included are those which have been investigated as CPAs for primary prevention of CRC. Comparators were another candidate CPA or placebo. We classified aspirin (ASA) into three groups for the analysis as described by the latest review for the USPSTF ${ }^{34}$ : high-dose or HDASA ( $>325 \mathrm{mg} /$ day), lowdose or LDASA ( $>100$ and $\leq 325 \mathrm{mg} /$ day), and very-low-dose or VLDASA ( $\leq 100 \mathrm{mg} /$ day $)$ aspirin.

\section{Outcomes of interest}

Primary efficacy outcomes of interest were incidence and mortality due to CRC. We present primary efficacy outcomes stratified by follow-up period after initiation of CPA as early risk ( $0-10$ years) and long-term risk ( $0-\geq 20$ years) since previous data showed that timing of intervention might impact outcomes. ${ }^{34}$ For safety outcomes, we collected data for interventions with evidence of efficacy in reducing either long-term CRC incidence or mortality (that is aspirin at different doses). Safety outcomes of interest were CV mortality and major GI bleeding events. The study investigators defined GI bleeding events that required hospitalization, transfusion, leading to death, as fatal or major. They also defined CV mortality as deaths due to any CV complications including myocardial infarction (MI), stroke (ischemic and hemorrhagic) or CV deaths (excluding deaths due to GI bleeding events).

\section{Data extraction and quality assessment}

Description of data extraction is reported in Supplement 2. Data were extracted independently by two reviewers (S.K.V, S.M.C). The most recent data were included if multiple publications of the same trial were retrieved. The study authors were contacted if required data were not available from publications. (Table S2.1 in Supplement 2). For all outcomes, we used the initial number of participants randomized to each trial arm and performed the analyses irrespective of how the authors of the original trials had analyzed the data (intentionto-treat principle).$^{43}$ Participants who were lost to follow-up 
were considered survivors, free of CRC or adverse events. Two reviewers (S.K.V, K.G.L) independently assessed the risk of bias (ROB) using the revised Cochrane risk of bias tool (RoB 2.0). ${ }^{44}$ Any discrepancies were resolved by consensus. The quality of evidence from NMA was evaluated using GRADEpro ${ }^{\circledR}$ GDT software online. ${ }^{45}$ Description of grading of evidence is provided in Methods S2.1 in Supplement 2.

\section{Data synthesis and statistical analysis}

A more detailed description of data synthesis and statistical analysis is provided in Methods S2.1 and Table S2.2 in Supplement 2. The relative intervention effects (ie, risk ratio $[R R]$ ) were estimated for individual studies. A direct meta-analysis was used to pool RRs using a random-effects model. Heterogeneity was assessed using the Cochran $Q$ test and the $I^{2}$ statistic. A random-effects NMA using consistency model was applied to compare all interventions using direct and indirect data. ${ }^{46,47}$ Inconsistency assumption was evaluated using the global inconsistency test by fitting design-by-treatment in the inconsistency model. Placebo was used as the common comparator in the network model. In the network meta-analysis, the surface under the cumulative ranking (SUCRA) curves were estimated to rank the intervention hierarchy. Higher SUCRA scores (ranging from 0 to 1) correspond to a higher ranking for prevention of CRC incidence and mortality and lower SUCRA scores correspond to a higher ranking for safety regarding $\mathrm{CV}$ mortality and GI bleeding events, compared with other CPAs. Publication bias was examined with a comparison-adjusted funnel plot. ${ }^{48}$ For statistical analysis, we used Stata version 14.0 (StataCorp, College Station, TX, USA). To assess the robustness of our primary efficacy outcomes, multiple pre-specified sensitivity analyses were performed by restricting studies with low-risk of bias, follow-up period of $0-\geq 20$ years after CPA initiation and various other assumptions (Table S2.3 in Supplement 2).

\section{Net clinical benefit (NCB) analysis}

Similar to approaches used in previous meta-analyses, ${ }^{53,54}$ an NCB analysis was performed to assess the balance of benefits from CRC mortality prevention ${ }^{34}$ and $\mathrm{CV}$ benefits ${ }^{49,50}$ with other risks ${ }^{51,52}$ of aspirin at different doses. Detailed description of NCB analysis is presented in Methods S2.2 in Supplement 2. Net survival gain (a way to represent the results of NCB) was calculatd by reviewing the estimated absolute effect of aspirin on long-term CRC mortality and CV mortality (the data for $\mathrm{CV}$ mortality comprised of mortality due to myocardial infarction [MI], stroke [ischemic and hemorrhagic], and other $\mathrm{CV}$ events apart from GI bleeding events) and subtracted the risk of mortality due to major GI bleeding events. With this approach, GI bleeding and hemorrhagic stroke associated with aspirin were comprehensively integrated into the equation. The NCB was calculated according to the formula, Net survival gain $(\%)=$ Difference in pooled risk estimates of CRC mortality between reference and intervention + Difference in pooled risk estimates of $\mathrm{CV}$ mortality between reference and intervention - Weight $\mathrm{x}$ difference in pooled risk estimates of major GI bleeding events between reference and intervention. For interpretation, a higher value of net survival gain corresponds to the more benefit gain for CPAs compared with the placebo. The weighting factor was determined by the proportion of death among patients with GI bleeding. Based on previously published reports (Methods S2.2), fatal GI bleeding event had approximately $6 \%$ of the effect of single mortality; therefore a weighting factor of 0.06 was used. Additional sensitivity analyses of $\mathrm{NCB}$ were conducted by varying weighting factors from 0.01 to 0.16 (Methods S2.2). The scatter plot between combined risk estimates of mortality from $\mathrm{CRC}$ and $\mathrm{CV}$ and pooled risk estimates of major GI bleeding was also produced to demonstrate the risk vs. benefit. Pooled risk estimate of the treatment with reference was calculated based on metaanalyses. ${ }^{55}$ To obtain the $95 \%$ confidence intervals of NCB, 1,000 bootstrap samples of risk estimates were performed for each intervention to calculate the risk differences among groups receiving placebo and various doses of aspirin. ${ }^{56,57} \mathrm{~A}$ series of threshold analyses were also performed by varying the weight for the case-fatality ratio of GI bleeding and by varying the incidence of GI bleeding to evaluate the impact of varying risks of GI bleeding on the NCB.

For NCB analysis, we collected data on CV mortality and major GI bleeding events from fair and good quality (criteria defined by the USPSTF) ${ }^{58}$ primary and secondary cardiovascular disease (CVD) prevention trials on aspirin in average-risk individuals for $\mathrm{CRC}$ as recently reported by the updated USPSTF reports. ${ }^{52}$

\section{Results}

\section{Study selection}

A PRISMA flow diagram depicting the search and selection process for the primary outcomes is presented in Figure S1.1 in Supplement 1. Our search identified a total of 4,573 citations after exclusion of duplicates. Among the 145 articles assessed for full text, 112 studies were excluded with reasons. In total, $21 \mathrm{RCTs}^{2-7,9-13,15-25}$ reporting the early risk of CRC incidence and $12 \mathrm{RCTs}^{8,24-31,59-64}$ reporting the long-term risk of either CRC incidence or mortality were included in our analysis. Another study ${ }^{65}$ reporting the early risk of 
CRC incidence was identified, but excluded with reasons (Supplement 2). Data on long-term risk of either CRC incidence or mortality from these 12 studies were identified from six post-trial observational studies ${ }^{8,28-31,59}$ and two individual participant data (IPD) meta-analyses. ${ }^{26,27}$ Additional unpublished relevant information were obtained from the authors of the Women Health Study (WHS), the Women's Antioxidant Cardiovascular Study (WACS), the Women's Antioxidant and Folic Acid Cardiovascular Study (WAFACS) and Physicians' Health Study II and used these data in the analysis of early risk of CRC incidence (Table S2.1 Supplement 2).

For safety outcomes, we collected data from 24 RCTs (including 6 RCTs reporting either the long-term risk of CRC incidence and mortality) on aspirin included in the updated USPSTF review $^{52}$ (Figure S3.1 in Supplement 3). Safety data from an additional trial (Dutch transient ischemic attack trial.; DTIA), ${ }^{64}$ which reported long-term CRC mortality, was also included.

\section{Characteristics of the included studies}

Table 1 describes the characteristics of all included studies (a more detailed description is provided in Tables S3.1-S3.12 in Supplement 3). In total, $21 \mathrm{RCTs}^{2-7,9-13,15-25,32}$ with 281,063 participants comparing 13 CPAs (Figure 1) were included in the NMA of early risk of CRC. Mean age of the population was 61 years. The length of follow-up from recruitment to study was $3.4-10$ years.

Among 12 RCTs reporting the long-term risk of CRC, 9 $\mathrm{RCTs}^{8,24,25,28,30,31,59-61}$ comparing 9 interventions with 160,101 participants (Figure 2A) treated for 3.2-10 years were included in the NMA of the long-term CRC incidence. Seven $\mathrm{RCTs}^{24,25,60-64}$ comparing seven interventions (Figure 2B) with 24,001 participants treated for approximately 2.6-10 years were included in the NMA of the long-term CRC mortality. Duration of follow-up among these 12 trials ranged from around six to more than 20 years. Mean age of the population was 60 years. All trials with long-term follow-up data were double-blinded and placebo-controlled, except one (open control design). ${ }^{24}$

Safety outcomes for aspirin at different doses were available from 25 RCTs (Tables S3.9, S3.10 in Supplement 3), including 11 primary and 14 secondary CVD prevention trials in average-risk individuals for $\mathrm{CRC}$ with an average followup of 1-10 years. Characteristics of all studies reporting safety outcomes are prsented in Table S3.10 in Supplement 3.

\section{Quality of included studies}

A detailed description of the risk of bias (ROB) assessment among included RCTs are presented in Tables S3.4 and S3.8 in Supplement 3. Among 21 RCTs reporting early risk of CRC (Table S3.4), 17 trials $^{4-7,9,10,12,15,16,18-23}$ had low ROB in most criteria. The remaining four trials were judged to be at high ROB. ${ }^{2,13,16,17}$ Among 12 RCTs reporting the long-term risk of CRC (Table S3.8), no studies were judged to be at high risk of bias in any domain. For safety outcomes analyses, we included only fair-to-good quality RCTs (as per the criteria defined by USPSTF ${ }^{58}$ from the updated USPSTF review. ${ }^{52}$ )

\section{Effects on the primary efficacy outcomes}

Treatment effects estimated from pairwise meta-analysis are presented in Supplement 4, without evidence of any substantial statistical heterogeneity. Treatment effects estimated from NMA for CPAs on early, long-term CRC incidence, and mortality are presented in Supplements 5,6 and 7, respectively.

\section{Early risk of CRC incidence}

Based on the NMA, there was no effect on the early risk of CRC incidence within approximately 3.4-10 years of initiation of HDASA (RR, 0.91 [95\% CI 0.55-1.53]), LDASA (RR, 1.15 [95\% CI 0.75-1.74]), VLDASA (RR, 0.89 [95\% CI 0.63-1.26]), antioxidants alone (RR, 0.94 [95\% CI 0.811.10]) or with ASAVLD (RR, 0.97 [95\% CI 0.69-1.37]), folic acid alone (RR, 1.00 [95\% CI 0.14-7.14]) or with vitamin B12 (RR, 0.94 [95\% CI 0.66-1.35]) or with vitamin B12 and B6 (RR, 1.17 [95\% CI 0.81-1.70]), calcium (RR, 0.19 [95\% CI 0.01-3.60]), and vitamin D (RR, 1.03 [95\% CI 0.59-1.82]), compared to placebo (Table S5.1 in Supplement 5). The results of NMA were similar to those obtained using standard pairwise meta-analysis and robust to the changes in sensitivity analyses (Figure S5.3 and Table S5.2 in Supplement 5).

\section{Long-term risk of CRC incidence}

NMA based on seven studies, ${ }^{8,24,25,28,30,31,59}$ for which the longterm incidence of CRC with a follow-up of more than 10 years suggested that, compared with placebo, HDASA (RR, 0.74 [95\% CI 0.57-0.97]) was ranked best for reducing the long-term CRC incidence, followed by VLDASA (RR, 0.81 [95\% CI 0.67-0.98]), calcium with vitamin D (RR, 0.96 [95\% CI 0.81-1.13]), LDASA (RR, 1.03 [95\% CI 0.83-1.27]), and any antioxidants (RR, 1.07 [95\% CI 0.89-1.28]) (Table S6.1 in Supplement 6). This is consistent with the pairwise metaanalysis (Figure S6.3 in Supplement 6). When we assessed comparative efficacy among aspirin at different doses, none of the treatments were superior over others (Figure 3). Overall, the results were robust to the changes in sensitivity analyses and HDASA, and VLDASA remained superior to placebo (Table S6.2 in Supplement 6). 


\section{Long-term risk of CRC mortality}

NMA based on $5 \mathrm{RCTs}^{24,25,62-64}$ with follow-up of more than 10 years suggested that, compared with placebo, LDASA (RR, 0.43 [95\% CI 0.23-0.81]) was ranked best for reducing long-term mortality due to CRC, followed by VLDASA (RR, 0.65 [95\% CI 0.45, 0.94]) and HDASA (RR, 0.71 [0.50-1.01]), respectively (Table S7.1 in Supplement 7). NMA results were consistent with the pairwise meta-analysis, except for LDASA (Figure S7.3 in Supplement 7). When we assessed comparative efficacy, LDASA was not superior to VLDASA (RR, 0.65 [95\% CI 0.34-1.25]) and HDASA (RR, 1.66 [95\% CI 0.84-3.29]) (Figure 3). The results from multiple sensitivity analyses were justifiably robust to the main analysis (Table S7.2 in Supplement 7).

\section{Safety outcomes}

We limited this analysis to the three CPAs (HDASA, LDASA, and VLDASA) with evidence of efficacy in reducing either long-term CRC incidence or mortality (Supplement 8). Results from NMA showed that HDASA ranked the lowest for safety (ie, major GI bleeding events) (RR, 4.04 [95\% CI 1.86-8.76]), followed by LDASA (RR, 1.85 [95\% CI 1.22-2.81]) and VLDASA (RR, 1.44 [95\% CI 1.15-1.81]). For CV mortality, there was no significant effect demonstrated by any doses of aspirin within approximately 1-10 years of initiation.

\section{Network consistency and small study effects}

The test of global inconsistency showed no inconsistency for any outcomes (Supplement 9). Comparison-adjusted plots showed no substantial evidence of small study effects, although the number of studies included in each comparison was small (Supplement 10).

\section{GRADE summary of the evidence}

Overall, the quality of evidence based on GRADE is generally rated as very-low to moderate. Detailed information on GRADE summary of evidence is presented in Supplement 11.

\section{Net clinical benefit analysis}

All 3 doses of aspirin were significantly better than placebo (Table S12.1 in Supplement 12). LDASA provided the highest net survival gain (\%) of $1.736(95 \%$ CI 1.010-2.434) followed by VLDASA (1.091 [95\% CI 0.614-1.573] and HDASA 0.908 [95\% CI 0.416-1.342], respectively). LDASA, VLDASA, and HDASA would result in a NCB of around 17, 11, and 9 deaths saved per 1,000 patients treated. The scatter plot (Figure 4) of combined risk estimates of CRC, CV mortality, and major GI bleeding reveals that LDASA has $0.7 \%$ less death compared to VLDASA with additional $0.1 \%$ increase in GI bleeding events (Tables S12.1, S12.2 and Method S12.1 in Supplement 12). The number needed to treat $(\mathrm{NNT})$ and number needed to harm $(\mathrm{NNH})$ for LDASA is 143 and 1,000 , respectively.

For the sensitivity analysis, the NCB of aspirin declines when the weighting factor for GI bleeding increases (varying from 0.01 to 0.16) (Figure S12.1 in Supplement 12). For the threshold analysis, when the case-fatality ratio of GI bleeding (weight) increases at 1.0, NCB of LDASA is still better than the NCB of VLDASA (Figure S12.2 in Supplement 12). The incidences of GI bleeding need to be as high as $25 \%$, ( 80 times higher risk of GI bleeding than normal), to demonstrate an equivalent NCB for LDASA and VLDASA (Figure S12.3 in Supplement 12).

\section{Discussion}

To the best of our knowledge, this is the first systematic review and network meta-analysis in the field of primary prevention of CRC by CPAs. The present review, combining direct and indirect evidence from 26 RCTs (297,476 participants) reporting either the early or long-term risk of CRC incidence or mortality, is the largest analysis in this field. Moreover, we were able to incorporate data of 4 trials for early risk of CRC incidence that were previously not analyzed (Table S2.2 in Supplement 2) and the DTIA trial (a trial testing different doses of aspirin without control), ${ }^{64}$ which was not included in the pairwise meta-analysis of earlier studies reporting the long-term risk of CRC mortality. ${ }^{27,34,37}$ Based on this comprehensive dataset and the use of NMA, we were able to conclude that, aspirin, antioxidants, calcium (with or without vitamin D), vitamin B6/12 and folic acid, either alone or in combination did not have appreciable protective effects against CRC within approximately 10 years of initiation. Additionally, our analysis suggests that aspirin at the dose range of 75-325 $\mathrm{mg}$ is a safe and effective intervention to reduce long-term $\mathrm{CRC}$ mortality and the benefit outweighs the risk of bleeding.

For antioxidants, various trials (Table S3.11 in Supplement 3 ) along with recent meta-analyses have failed to detect any protective effects despite supportive evidence from in vitro, in vivo, and observational studies. ${ }^{66}$ It is important to note however that most antioxidants trials are relatively short in duration and therefore make it difficult to detect any appreciable effects that require long-term follow-up. In addition, antioxidants are a diverse group of compounds. Readers 
Table I Brief description of included studies in network meta-analysis

\begin{tabular}{|c|c|c|c|c|}
\hline Author, year (reference) & $\begin{array}{l}\text { Study } \\
\text { name }\end{array}$ & $\begin{array}{l}\text { Study design (double } \\
\text { blind, placebo controlled, } \\
\text { randomized trial) }\end{array}$ & Population & $\begin{array}{l}\text { Number of } \\
\text { participants }\end{array}$ \\
\hline \multicolumn{5}{|c|}{ Randomized controlled trials reported early risk of colorectal cancer incidence } \\
\hline $\begin{array}{l}\text { Gann et al (1993)/ Hennekens } \\
\text { et al }(1996)^{2,3}\end{array}$ & $\mathrm{PHS}^{\mathrm{a}}$ & Yes, $2 \times 2$ factorial & Male physicians & 22,071 \\
\hline Peto et al $(1988)^{24,26}$ & BDAT & Open control, parallel & Male physicians & 5,139 \\
\hline Farrell et al $(1991)^{25,26}$ & UK-TIA & Yes, parallel, 3-arms & History of TIA or minor ischemic stroke & 2,449 \\
\hline Omenn et al $(1996)^{4}$ & CARET & Yes, parallel & $\begin{array}{l}\text { Cigarette smokers, former smokers, and } \\
\text { workers exposed to asbestos }\end{array}$ & $|8,3| 4$ \\
\hline HPS group $(2002)^{5}$ & HPS & Yes, $2 \times 2$ factorial & $\begin{array}{l}\text { History of coronary and other occlusive } \\
\text { arterial disease or diabetes }\end{array}$ & 20,536 \\
\hline Duffield-Lillico et al $(2002)^{6}$ & NPCT & Yes, parallel & History of non-melanoma skin cancer & 1,312 \\
\hline Virtamo et al $(2003)^{7,8}$ & ATBC & Yes, $2 \times 2$ factorial & Male cigarette smokers & 29,133 \\
\hline Trivedi et al $(2003)^{9}$ & NA & Yes, parallel & Physicians and the general practice population & 2,686 \\
\hline Zhu et al $(2003)^{13}$ & NA & Unclear, parallel-4 arms & History of atrophic gastritis & 216 \\
\hline Hercberg et al $(2004)^{10}$ & SU.VI.MAX & Yes, parallel & General population & 13,017 \\
\hline $\begin{array}{l}\text { Lonn et al (2005)/ Lonn et al } \\
(2006)^{11,12}\end{array}$ & $\mathrm{HOPE}^{\mathrm{a}}$ & Yes, $2 \times 2$ factorial & History of CV diseases or diabetes & 9,541 \\
\hline Cook et al $(2005)^{19}$ & $\mathrm{WHS}^{\mathrm{a}}$ & Yes, $2 \times 2$ factorial & Female health professionals & 39,876 \\
\hline Wactawski-Wende et al (2006) $)^{15}$ & WHI & Yes, parallel & Postmenopausal women & 36,282 \\
\hline Lappe et al $(2007)^{16}$ & NA & Yes, parallel, 3-arms & Postmenopausal women & $\mathrm{I}, \mathrm{I79}$ \\
\hline Lin et al $(2009)^{17}$ & WACS ${ }^{a}$ & Yes, $2 \times 2 \times 2 \times 2$ factorial & $\begin{array}{l}\text { Female health professionals at high risk of } \mathrm{CV} \\
\text { disease }\end{array}$ & $2,729^{d}$ \\
\hline Zhang et al $(2008)^{18}$ & WAFACS & Yes, $2 \times 2 \times 2 \times 2$ factorial & $\begin{array}{l}\text { Female health professionals at high risk of CV } \\
\text { disease }\end{array}$ & $5,442^{\mathrm{d}}$ \\
\hline Lippman et al $(2009)^{20}$ & SELECT & Yes, $2 \times 2$ factorial & General population (men only) & 35,533 \\
\hline Gaziano et al (2009) 21 & PHS II & Yes, $2 \times 2 \times 2 \times 2$ factorial & Male physicians & $14,520^{d}$ \\
\hline Armitage et al $(2010)^{22}$ & SEARCH & Yes, $2 \times 2$ factorial & History of MI & 12,064 \\
\hline Hankey et al $(2012)^{23}$ & VITATOPS & Yes, parallel & $\begin{array}{l}\text { History of recent stroke or transient ischemic } \\
\text { attack }\end{array}$ & 8,164 \\
\hline Gao et al $(2013)^{32}$ & NA & Open-control, parallel & General population & 860 \\
\hline \multicolumn{5}{|c|}{ Randomized controlled trials reported the long-term risk of either colorectal cancer incidence or mortality } \\
\hline Peto et al $(1988)^{24,27}$ & BDAT & Open control, parallel & Male physicians & 5,139 \\
\hline Farrell et al $(|99|)^{25,27}$ & UK-TIA & Yes, parallel, 3-arms & History of TIA or minor ischemic stroke & 2,449 \\
\hline Stürmer et al $(1998)^{59}$ & $\mathrm{PHS}^{\mathrm{a}}$ & Yes, $2 \times 2$ factorial & Male physicians & 22,071 \\
\hline Virtamo et al $(2003)^{8}$ & ATBC & Yes, $2 \times 2$ factorial & Male cigarette smokers & 29,133 \\
\hline Goodman et al $(2004)^{28}$ & CARET & Yes, parallel & $\begin{array}{l}\text { Cigarette smokers, former smokers, and } \\
\text { workers exposed to asbestos }\end{array}$ & $18,3 \mid 4$ \\
\hline Ebbing et al $(2009)^{29,60,61}$ & $\begin{array}{l}\text { NORVIT/ } \\
\text { WENBIT }^{\mathrm{a}}\end{array}$ & $\begin{array}{l}\text { Yes, Combined analysis and } \\
\text { extended follow-up of } 2 \text { RCTs. }\end{array}$ & History of ischemic heart disease & $\begin{array}{l}6,837 \text { (both } \\
\text { trials) }\end{array}$ \\
\hline Cook et al $(2013)^{30}$ & WHS & Yes, $2 \times 2$ factorial & Female health professionals & 39,876 \\
\hline Cauley et al $(2013)^{31}$ & WHI & Yes, parallel & Postmenopausal women & 36,282 \\
\hline \multirow[t]{3}{*}{ Rothwell et al $(2010)^{27}$} & $\mathrm{TPT}^{62}$ & Yes, $2 \times 2$ factorial & High risk for IHD & 5,085 \\
\hline & $\mathrm{SALT}^{63}$ & Yes, parallel & History of TIA or stroke & 1,360 \\
\hline & $\mathrm{DTIA}^{64}$ & No placebo, parallel & History of TIA or stroke & $3,|3|$ \\
\hline
\end{tabular}

Notes: A more detailed description with efficacy outcomes from all individual studies is reported in Supplement 3.WHS and PHS are alternate-day dose studies (I00 mg every other day (defined as ASA-VLD) and $325 \mathrm{mg}$ every other day (ASA-LD), respectively). ${ }^{34}$ a Detailed description of studies provided in Table S2.2 in Supplement $2 .{ }^{\circ}$ Range. ${ }^{\text {C Median. }}$

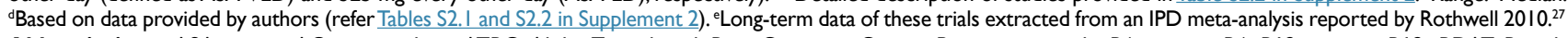
Abbreviations: ASA, asprin; AO, antioxidant; ATBC, Alpha-Tocopherol, Beta-Carotene Cancer Prevention study; B6, vitamin B6; BI2, vitamin BI2; BDAT, British Doctors Aspirin Trial; CA, calcium; CARET, carotene and retinol efficacy trial; CTL, control; CV, cardiovascular; DTIA, Dutch Transient Ischaemic Attack Trial; FA, folic acid; FAVB, folic acid with vitamin B6 and BI2; GI, gastrointestinal; HD, high-dose; HOPE, Heart Outcomes Prevention Evaluation trial; HPS, Heart Protection Study; IHD, ischemic heart disease; LD, low-dose; MI, myocardial infarction; NPCT, nutritional prevention of cancer trial; NORVIT, Norwegian Vitamin Trial; PHS, Physicians' Health Study; PLB, placebo; SALT, Swedish Aspirin Low Dose Trial; SEARCH, Study of the Effectiveness of Additional Reductions in Cholesterol and Homocysteine; SELECT, Selenium and Vitamin E Cancer Prevention Trial; SU.VI.MAX, Supplémentation en Vitamines et Minéraux Antioxydants study; TPT, Thrombosis Prevention Trial; TIA, transient ischemic attack; UK-TIA, UK Transient Ischaemic Attack Aspirin Trial;VD, vitamin D, VITATOPS, Vitamins to Prevent Stroke Trial; VLD, very-low-dose; WACS, The Women's Antioxidant Cardiovascular Study; WAFACS, Women's Antioxidant and Folic Acid Cardiovascular Study; WENBIT, Western Norway B Vitamin Intervention Trial;WHI, women's health initiative; WHS, Women's Health Study. 


\begin{tabular}{|c|c|c|c|c|c|}
\hline $\begin{array}{l}\text { Mean age } \\
\text { (years) }\end{array}$ & Male \% & Interventions & $\begin{array}{l}\text { Mean intended } \\
\text { treatment } \\
\text { duration (years) }\end{array}$ & $\begin{array}{l}\text { Mean follow- } \\
\text { up (years) }\end{array}$ & Outcome measures \\
\hline 53 & 100 & ASA-LD; AOs; PLB & $\begin{array}{l}5 \text { (ASA-LD); } 12 \\
(\mathrm{AO})\end{array}$ & $\begin{array}{l}5 \text { (ASA-LD); } 12 \\
(\mathrm{AO})\end{array}$ & $\mathrm{CV}$ events, cancers and overall mortality \\
\hline 62 & 100 & ASA-HD; CTL & 6 & Up to 9 years $^{\mathrm{b}}$ & $\mathrm{CV}$ events and mortality from $\mathrm{CV}$ causes \\
\hline 60 & 73 & ASA-LD; ASA-HD; PLB & $4.4^{c}(1-7$ years $)$ & Up to 9 years $^{b}$ & $\begin{array}{l}\mathrm{CV} \text { events, mortality from vascular and non-vascular } \\
\text { causes }\end{array}$ \\
\hline 57 & 66 & AOs; PLB & 4 & 4 & Lung cancer, other cancers and overall mortality \\
\hline $40-80^{\mathrm{b}}$ & 75 & AOs; PLB & 5 & 5 & Major coronary events, cancers and overall mortality \\
\hline 63 & 75 & AOs; PLB & 4.5 & 7.4 & $\begin{array}{l}\text { Non-melanoma skin cancer, other cancers and } \\
\text { overall mortality }\end{array}$ \\
\hline 57 & 100 & AOs; PLB & 6.1 & 6.1 & Lung cancer, other cancers and overall mortality \\
\hline 75 & 76 & VD; PLB & 5 & 5 & Fractures, cancers, CV events and overall mortality \\
\hline 56 & 63 & $\mathrm{FA}+\mathrm{BI} 2 ; \mathrm{AOs} ; \mathrm{PLB}$ & 2 & 6 & Stomach cancer and other $\mathrm{Gl}$ cancers \\
\hline 49 & 39 & AOs; PLB & 7.5 & 7.5 & $\mathrm{CV}$ events, cancers and overall mortality \\
\hline 66 & 73 & AOs; FA+B6+BI2; PLB & 4.5 & 4.5 & $\begin{array}{l}\text { Cancer incidence, cancer deaths, major } \mathrm{CV} \text { events } \\
\text { and overall mortality }\end{array}$ \\
\hline 55 & 0 & $\begin{array}{l}\text { ASA-VLD; AOs; ASA- } \\
\text { VLD+AOs; PLB }\end{array}$ & 10.1 & 10.1 & Cancer or $\mathrm{CV}$ events \\
\hline 59 & 0 & $C A+V D ; P L B$ & 7 & 7 & Fractures and cancers \\
\hline 67 & 0 & $\mathrm{CA} ; \mathrm{CA}+\mathrm{VD} ; \mathrm{PLB}$ & 4 & 4 & Fractures and cancers \\
\hline 60 & 0 & AOs; PLB & $8^{d}$ & $8^{d}$ & $\mathrm{CV}$ events, cancers and overall mortality \\
\hline 63 & 0 & $\begin{array}{l}A O s ; F A V B ; F A V B+A O s ; \\
P L B\end{array}$ & $6.8^{\mathrm{d}}$ & $6.8^{\mathrm{d}}$ & $\mathrm{CV}$ events, cancers and overall mortality \\
\hline $62-6^{c}$ & 100 & AOs; PLB & 5.5 & 5.5 & Prostate cancer and other cancers \\
\hline 64 & 100 & AOs; PLB & 8 & 8 & $\mathrm{CV}$ diseases, prostate and total cancer \\
\hline 64 & 83 & $\mathrm{FA}+\mathrm{B} \mid 2 ; \mathrm{PLB}$ & 6.7 & 6.7 & $\mathrm{CV}$ events and cancers \\
\hline 62 & 64 & FAVB; PLB & 3.4 & 3.4 & $\mathrm{CV}$ events, cancers and overall mortality \\
\hline 61 & 50 & $\mathrm{FA} ; \mathrm{CTL}$ & 3 & 3 & Colorectal adenomas \\
\hline 62 & 100 & ASA-HD; CTL & $\begin{array}{l}6 \text { (at least } 5 \text { years } \\
\text { for all patients) }\end{array}$ & up to $23^{a}$ & $\mathrm{CV}$ events and mortality from $\mathrm{CV}$ causes \\
\hline 60 & 73 & ASA-LD; ASA-HD; PLB & $4.4^{c}(\mathrm{I}-7$ years $)$ & up to $2 \mathrm{I}-27^{\text {a }}$ & $\begin{array}{l}\mathrm{CV} \text { events, mortality from vascular and non-vascular } \\
\text { causes }\end{array}$ \\
\hline 53 & 100 & ASA-LD; PLB & 5 & 12 & $\mathrm{Ml}$ and other $\mathrm{CV}$ events; cancer \\
\hline 57.2 & 100 & AOs; PLB & 6.1 & 12 & Cancer incidence and mortality \\
\hline 57 & 66 & AOs; PLB & 4 & 10 & Lung cancer and other cancers \\
\hline 62 & 76 & FAVB; FA+BI2; PLB & 3.2 & 6.4 & CV outcomes \\
\hline 55 & 0 & ASA-VLD; CTL & 10.1 & 18 & Any invasive cancer \\
\hline 59 & 0 & CA+VD; PLB & 7 & 11 & Fractures and colorectal cancer \\
\hline 57.5 & 100 & ASA-VLD; PLB & 7 (at least 5 years) & Up to $17-20^{b}$ & Ischemic heart diseases \\
\hline 70 & 66 & ASA-VLD; PLB & 2.7 ( $1-5$ years $)$ & $U_{p}$ to $18-23^{b}$ & Composite outcome of stroke or death from any causes \\
\hline 65.3 & 65 & ASA-VLD; ASA-LD & $2.6(\mathrm{I}-4$ years $)$ & Up to $17^{\mathrm{b}}$ & Death from CV causes \\
\hline
\end{tabular}




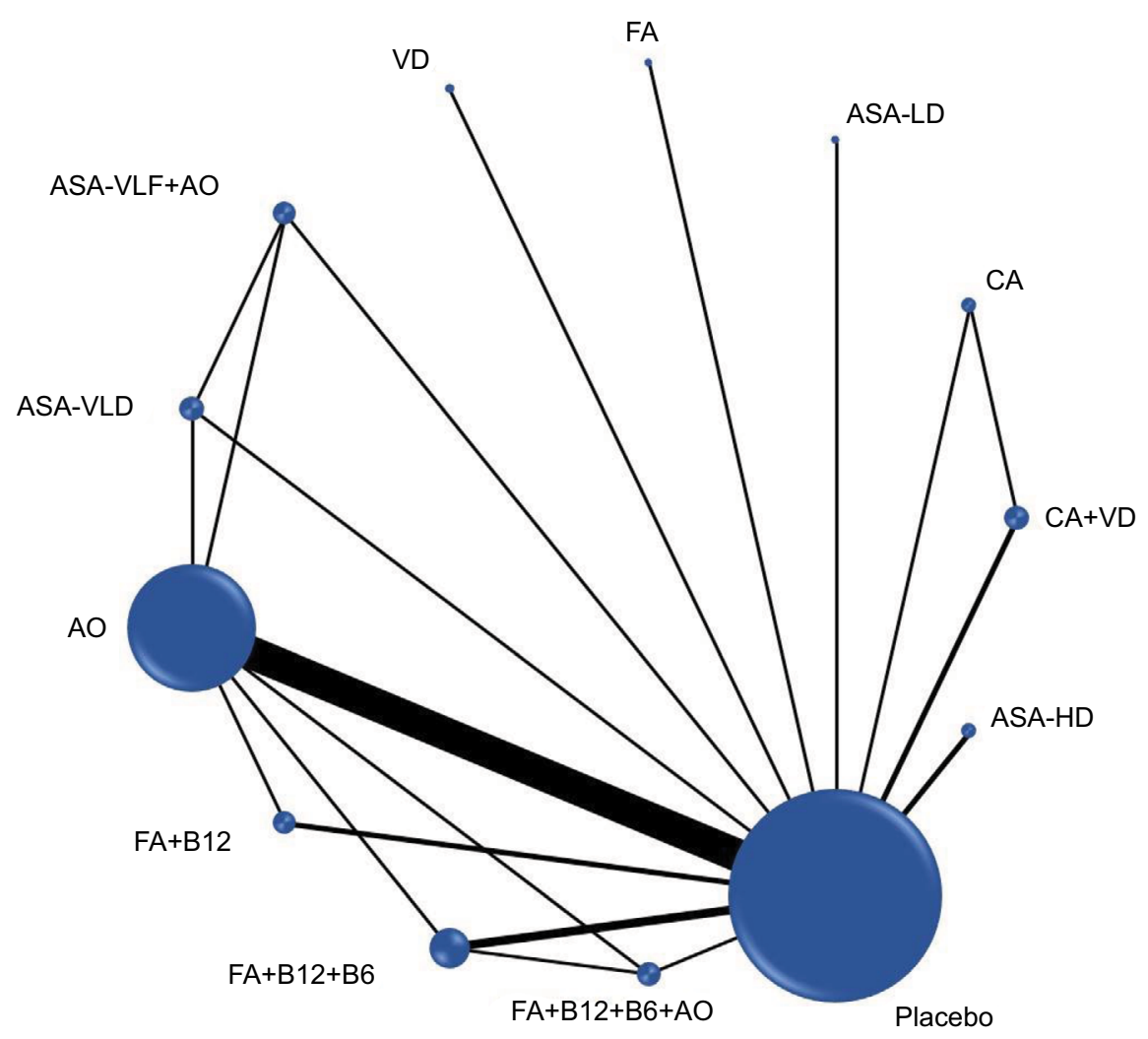

Figure I Network plot of chemopreventive agents tested in RCTs for early risk of CRC incidence.

Abbreviations: RCT, randomized controlled trials; CRC, colorectal cancer; ASA, asprin; HD, high-dose; LD, low-dose; VLD, very-low-dose; VitaminBI2; B6, vitamin B6; CA, calcium; AO, antioxidants; FA, folic acid; VD, vitamin D.
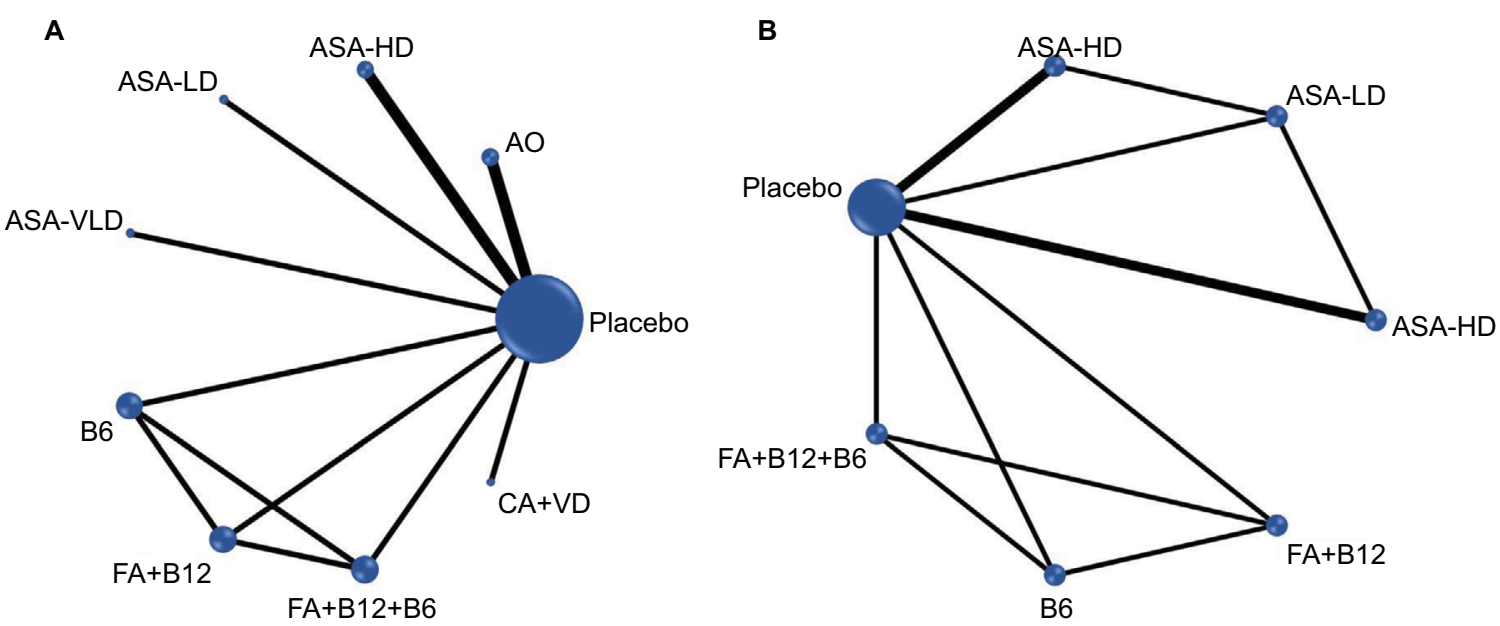

Figure 2 Network plots of chemopreventive agents tested in RCTS (follow-up $0-\geq 20$ years) for (A) long-term risk of CRC incidence (B) long-term risk of CRC mortality. Abbreviations: RCT, randomized controlled trials; CRC, colorectal cancer; ASA, asprin; HD, high-dose; LD, low-dose; VLD, very-low-dose; VitaminBI2; B6, vitamin B6; CA, calcium; AO, antioxidants; FA, folic acid; VD, vitamin D.

must, therefore, note that the findings of our analysis only applied to beta-carotene, vitamin A, vitamin E, vitamin C, selenium, and zinc.

Observational studies suggested a relationship among calcium and vitamin D levels and CRC. ${ }^{67,68} \mathrm{~A}$ recent meta-analysis suggested that calcium may have a moderate protective effect on CRC recurrence. ${ }^{69}$ However, we did not find any effects of calcium (alone or with vitamin D). A recent phase-2 trial showed that high-dose vitamin D3 (loading dose of 8,000 IU/ day orally for 2 weeks followed by 4,000 IU/day) significantly improved survival in patients with metastatic CRC. ${ }^{70}$ It should be noted that low dose (400 IU/day) of vitamin D was used in 


\begin{tabular}{|c|c|c|c|}
\hline ASA-HD & $\begin{array}{c}0.72 \\
(0.51,1.01)\end{array}$ & $\begin{array}{c}0.91 \\
(0.66,1.26)\end{array}$ & $\begin{array}{c}0.74 \\
(0.57,0.97)\end{array}$ \\
\hline $\begin{array}{c}1.66 \\
(0.84,3.29)\end{array}$ & ASA-LD & $(0.96,1.68)$ & $(0.83,1.27)$ \\
\hline 1.08 & 0.65 & ASA-VLD & $(0.67,0.98)$ \\
$(0.66,1.79)$ & $(0.34,1.25)$ & & 0.81 \\
\hline 0.71 & 0.43 & 0.66 & PCB \\
$(0.50,1.01)$ & $(0.23,0.81)$ & $(0.45,0.95)$ & \\
\hline
\end{tabular}

\begin{tabular}{|c|c|c|c|}
\hline \multicolumn{4}{|c|}{ CV mortality } \\
ASA-HD & $\begin{array}{c}1.05 \\
(0.88,1.25)\end{array}$ & $\begin{array}{c}1.01 \\
(0.86,1.18)\end{array}$ & $\begin{array}{c}0.93 \\
(0.83,1.04)\end{array}$ \\
\hline $\begin{array}{c}2.18 \\
(1.08,4.41)\end{array}$ & ASA-LD & $\begin{array}{c}0.96 \\
(0.81,1.14)\end{array}$ & $\begin{array}{c}0.89 \\
(0.77,1.02)\end{array}$ \\
\hline 2.80 & 1.28 & ASA-VLD & $\begin{array}{c}0.92 \\
(0.82,1.03)\end{array}$ \\
\hline$(1.25,6.26)$ & $(0.80,2.05)$ & & PCB \\
$(1.86,8.76)$ & $(1.22,2.81)$ & $(1.15,1.81)$ & \\
\hline
\end{tabular}

Major GI bleeding

Figure 3 Efficacy and safety of aspirin for colorectal cancer in network meta-analysis.

Notes: Efficacy outcomes are long-term CRC incidence and CRC mortality. Safety outcomes are major GI bleeding events and CV deaths. Risk ratio (95\% credible interval) of comparisons for each outcome is in cells in common between column-defining and row-defining treatment. Comparison between treatments should read from row to column for CRC event and CV mortality and column to row for CRC mortality and major Gl bleeding events. For risk of CRC event and CV mortality, risk ratio <I favor row-defining treatment. For risk of $C R C$ mortality and $\mathrm{Gl}$ bleeding events, risk ratio, $<I$ favor column-defining treatment. Orange shaded results indicate statistical significance. Abbreviations: CRC, colorectal cancer; CV, cardiovascular; GI, gastrointestinal; ASA, asprin; HD, high-dose; LD, low-dose; VLD, very-low-dose; PCB, placebo.

all primary prevention trials (and not in the form of vitamin D3). ${ }^{69,71}$ As a result, future trials of vitamin D may need to explore both different forms and various dosing of vitamin D.

Previous studies of folic acid supplementation on CRC showed inconsistent results. ${ }^{40,72,73}$ We did not find either a decrease or an increase in the risk of CRC in any folic intervention (Table S3.12 in Supplement 3). A recent study suggested that the effect of folic acid may depend upon the existing level of blood folate along with methylenetetrahydrofolate reductase (MTHFR) genotype. ${ }^{74}$ Therefore, the effect of folic acid on $\mathrm{CRC}$ may require further investigation based on those factors.

Over the past few decades, data concerning aspirin derived from RCTs and meta-analyses generated mostly discouraging findings for CRC prevention after mediumterm, in-trial follow-up ( $\leq 10$ years). ${ }^{2,19,36,37}$ However, recent extended follow-up of RCTs has shown remarkably consistent evidence on the protective effect of aspirin against longterm CRC incidence and mortality. ${ }^{27,30,34}$ The 2016 USPSTF guideline ${ }^{35,75}$ suggested the use of aspirin ( $<100 \mathrm{mg} /$ day) for primary CRC prevention in people who have a $10 \%$ or greater 10 -year risk for CVD and who are not at an increased risk of bleeding. This recommendation was derived from pairwise meta-analysis and multi-criteria decision analysis (MCDA) using a microsimulation model to systematically estimate the balance of benefits and harms through the gain in net life years and quality-adjusted life years. ${ }^{34,50}$ Our analysis took different approaches. First, we explored the comparative efficacy of different CPAs including aspirin to ensure that all interventions in the landscape were represented and analyzed. ${ }^{27,34,36-40}$ Our results lend strong support to USPSTF by showing that, based on the most current data, aspirin is the only effective CPA compared to placebo and other CPAs.

While USPSTF analysis attempted to evaluate the effect of doses and duration of treatment, no meaningful analysis was made due to the limited amount of direct head-to-head trials of different doses of aspirin. To extend beyond USPSTF analysis, we did an NMA to comprehensively compare 3 doses of aspirin and able to show detailed differences in efficacy and safety of aspirin at different doses (Figure 3). We believe that this analysis is useful since aspirin demonstrated a dosedependent effect relating to the risks of GI bleeding events and hemorrhagic stroke. ${ }^{76}$ Therefore, selection of aspirin dose for long-term use requires striking the right balance between benefit and risk. To tackle this issue, we used NCB to simultaneously evaluate effects of aspirin on $\mathrm{CRC}$ and $\mathrm{CV}$ mortality along with major GI bleeding of different aspirin doses. Based on this comprehensive evaluation investigating the multidimensional effects of aspirin, we were able to show that both LDASA and VLDASA appeared to strike an optimal balance on CV and CRC mortality vs major GI bleeding (Figure 4). Based on analysis with different weighting on major GI bleeding event, LDASA seemed to provide the highest net survival gain among different doses of aspirin. However, we caution readers that this result is far from definite and should be taken as hypothesis generated for further research to try to identify the optimal dose of aspirin for CRC prevention, cardiovascular disease prevention along with acceptable adverse drug reaction. As a result, until more evidence becomes available, it may be prudent to consider both low-dose (100-325 mg/ day) and very-low-dose aspirin ( $75-100 \mathrm{mg}$ /day) as the viable options for both CRC and cardiovascular disease prevention.

\section{Limitations of study}

Our study has several important limitations. First, most data on long-term $\mathrm{CRC}$ incidence and mortality were collected post hoc as a part of follow-up trials that included other outcomes as predefined endpoints, rather than CRC incidence or mortality. The completeness in capturing those events may be questionable. Second, differences in patient population, trial conducts, and trial methodology across studies may 


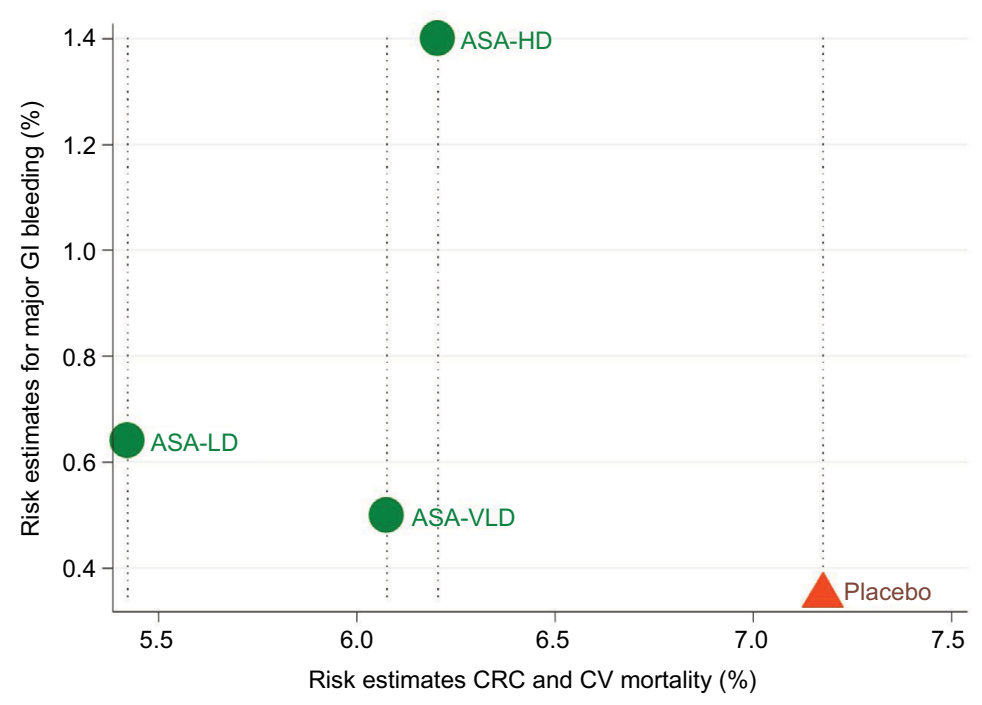

Figure 4 Scatter plot of combined risk estimates of CRC and CV mortality vs pooled risk estimates for major GI bleeding. Note: Treatments lying in the left lower corner are more effective and acceptable than the other treatments.

Abbreviations: CRC, colorectal cancer; CV, cardiovascular; GI, gastrointestinal; ASA, aspirin; HD, high-dose; LD, low-dose; VLD, very-low-dose.

create an inherent heterogeneity especially the difference in treatment duration and follow-up period. Third, our analysis on the effects of aspirin doses can be perceived as hypothesis generation since data are still too limited to make a definitive conclusion on the dose-specific effects of aspirin. However, we still believe that aspirin at the dose of $75-325 \mathrm{mg} /$ day is best supported by not only our study but also previous reports. Until new large RCTs comparing different doses of aspirin are available, we believe that our findings offer a range of aspirin dose for clinician and patient to discuss and make a shared decision to choose what dose of aspirin may suit the differential risk-benefit profile of each patient. While recognizing the impact of age on the risk-benefit of aspirin, we were unable to perform detailed analysis based on age due to the lack of individual patient data. Based on this limitation along with the definite incremental risk of aspirin with advanced age and lack of robust data to support efficacy for long-term CRC prevention in the elderly, we caution the readers to avoid extrapolating these results toward elderly patients.

\section{Conclusions and policy implications}

Our analysis suggests that aspirin was the only intervention that showed protective effects with potential dosedependent effects while none of the other CPAs was found to be effective. Aspirin at the dose range of $75-325 \mathrm{mg}$ /day is a safe and effective primary prevention for long-term $\mathrm{CRC}$ among people at average risk. For patients with low risk of bleeding, low-dose aspirin (>100-325 mg/day) may slightly be more attractive due to a larger reduction in CRC mortality and the best net clinical benefit. For patients at high risk of bleeding, very-low-dose aspirin $(<100 \mathrm{mg} /$ day) might be appropriate due to its best safety profile especially GI bleeding. There may potentially be differential effects among various doses of aspirin that needs further investigation.

\section{Data sharing}

Technical appendix and dataset available from the corresponding authors.

\section{Acknowledgments}

The authors thank Prof Dato, Dr (Mrs) Kew Siang Tong, School of Medicine, International Medical University and Dr Muhammad Radzi bin Abu Hassan, Head of Gastroenterology Service, Ministry of Health, Malaysia for their expertise and advice during the development of the protocol. The authors wish to thank Prof Brian L Furman, Strathclyde Institute of Pharmacy and Biomedical Sciences, Glasgow, UK, for his valuable comments and support which helped to improve the manuscript and $\mathrm{Mr}$ Razman Shah Mohd Razali, reference librarian, International Medical University, for providing the full-text articles whenever needed. Finally, the authors wish to thank Prof Julie E Buring, Prof JoAnn E Manson, Dr Howard D Sesso and Dr Martin J Vandenburgh from Harvard Medical School, Brigham and Women's Hospital, Massachusetts, for sharing data from their studies. This research received no specific grant from any funding agency in the public, commercial, or not-for-profit sectors. 


\section{Author contributions}

SKV, NC, SN, KGL, SS and PJ designed and organized research. NC supervised the study. SKV, KGL and SMC acquired, analyzed and interpreted data. SKV, PJ and NT performed the statistical analysis. SKV and SN wrote the manuscript. NC, SN, CR and PP revised the review. All authors contributed toward data analysis, drafting and critically revising the paper, gave final approval of the version to be published, and agree to be accountable for all aspects of the work.

\section{Disclosure}

The authors report no conflicts of interest in this work.

\section{References}

1. Ferlay J, Soerjomataram I, Dikshit R, et al. Cancer incidence and mortality worldwide: sources, methods and major patterns in GLOBOCAN 2012. Int J Cancer. 2015;136(5):E359-E386.

2. Gann PH, Manson JE, Glynn RJ, Buring JE, Hennekens CH. Low-dose aspirin and incidence of colorectal tumors in a randomized trial. J Natl Cancer Inst. 1993;85(15):1220-1224.

3. Hennekens CH, Buring JE, Manson JE, et al. Lack of effect of longterm supplementation with beta carotene on the incidence of malignant neoplasms and cardiovascular disease. $N$ Engl J Med. 1996;334(18): 1145-1149.

4. Omenn GS, Goodman GE, Thornquist MD, et al. Effects of a combination of beta carotene and vitamin A on lung cancer and cardiovascular disease. N Engl J Med. 1996;334(18):1150-1155.

5. Heart Protection Study Collaborative Group. MRC/BHF Heart Protection Study of antioxidant vitamin supplementation in 20,536 high-risk individuals: a randomised placebo-controlled trial. Lancet. 2002;360(9326):23-33.

6. Duffield-Lillico AJ, Reid ME, Turnbull BW. Baseline characteristics and the effect of selenium supplementation on cancer incidence in a randomized clinical trial: a summary report of the Nutritional Prevention of Cancer Trial. Cancer Epidemiol Biomark Prev Publ Am Assoc Cancer Res Cosponsored Am Soc Prev Oncol. 2002;11(7):630-639.

7. Albanes D, Malila N, Taylor PR, et al. Effects of supplemental alphatocopherol and beta-carotene on colorectal cancer: results from a controlled trial (Finland). Cancer Causes Control. 2000;11(3):197-205.

8. Virtamo J, Pietinen P, Huttunen JK, et al. Incidence of cancer and mortality following alpha-tocopherol and beta-carotene supplementation: a postintervention follow-up. JAMA. 2003;290(4):476-485.

9. Trivedi DP, Doll R, Khaw KT. Effect of four monthly oral vitamin D3 (cholecalciferol) supplementation on fractures and mortality in men and women living in the community: randomised double blind controlled trial. BMJ. 2003;326(7387):469.

10. Hercberg S, Galan P, Preziosi P, et al. The SU.VI.MAX Study: a randomized, placebo-controlled trial of the health effects of antioxidant vitamins and minerals. Arch Intern Med. 2004;164(21):2335-2342.

11. Lonn E, Bosch J, Yusuf S, et al. Effects of long-term vitamin E supplementation on cardiovascular events and cancer: a randomized controlled trial. JAMA. 2005;293(11):1338-1347.

12. Lonn E, Yusuf S, Arnold MJ, et al. Homocysteine lowering with folic acid and B vitamins in vascular disease. N Engl J Med. 2006;354(15): 1567-1577.

13. Zhu S, Mason J, Shi Y, et al. The effect of folic acid on the development of stomach and other gastrointestinal cancers. Chin Med J. 2003;116(1):15-19.

14. Lee IM, Cook NR, Gaziano JM, et al. Vitamin E in the primary prevention of cardiovascular disease and cancer: the Women's Health Study: a randomized controlled trial. JAMA. 2005;294(1):56-65.
15. Wactawski-Wende J, Kotchen JM, Anderson GL, et al. Calcium plus vitamin D supplementation and the risk of colorectal cancer. $N$ Engl J Med. 2006;354(7):684-696.

16. Lappe JM, Travers-Gustafson D, Davies KM, Recker RR, Heaney RP. Vitamin D and calcium supplementation reduces cancer risk: results of a randomized trial. Am J Clin Nutr. 2007;85(6):1586-1591.

17. Lin J, Cook NR, Albert C, et al. Vitamins $\mathrm{C}$ and $\mathrm{E}$ and beta carotene supplementation and cancer risk: a randomized controlled trial. J Natl Cancer Inst. 2009;101(1):14-23.

18. Zhang SM, Cook NR, Albert CM, Gaziano JM, Buring JE, Manson JE. Effect of combined folic acid, vitamin B6, and vitamin B12 on cancer risk in women: a randomized trial. JAMA. 2008;300(17):2012-2021.

19. Cook NR, Lee IM, Gaziano JM, et al. Low-dose aspirin in the primary prevention of cancer: the Women's Health Study: a randomized controlled trial. JAMA. 2005;294(1):47-55.

20. Lippman SM, Klein EA, Goodman PJ, et al. Effect of selenium and vitamin $\mathrm{E}$ on risk of prostate cancer and other cancers: the Selenium and Vitamin E Cancer Prevention Trial (SELECT). JAMA. 2009;301(1):39-51.

21. Gaziano JM, Glynn RJ, Christen WG, et al. Vitamins E and C in the prevention of prostate and total cancer in men: the Physicians' Health Study II randomized controlled trial. JAMA. 2009;301(1):52-62.

22. Study of the Effectiveness of Additional Reductions in Cholesterol and Homocysteine (SEARCH) Collaborative Group, Armitage JM, Bowman L, et al. Effects of homocysteine-lowering with folic acid plus vitamin B12 vs placebo on mortality and major morbidity in myocardial infarction survivors: a randomized trial. JAMA. 2010;303(24): 2486-2494.

23. Hankey GJ, Eikelboom JW, Yi Q, et al. Treatment with B vitamins and incidence of cancer in patients with previous stroke or transient ischemic attack: results of a randomized placebo-controlled trial. Stroke. 2012;43(6):1572-1577.

24. Peto R, Gray R, Collins R, et al. Randomised trial of prophylactic daily aspirin in British male doctors. BMJ. 1988;296(6618):313-316.

25. Farrell B, Godwin J, Richards S, Warlow C. The United Kingdom transient ischaemic attack (UK-TIA) aspirin trial: final results. J Neurol Neurosurg Psychiatry. 1991;54(12):1044-1054.

26. Flossmann E, Rothwell PM. British Doctors Aspirin Trial and the UK-TIA Aspirin Trial. Effect of aspirin on long-term risk of colorectal cancer: consistent evidence from randomised and observational studies. Lancet Lond Engl. 2007;369(9573):1603-1613.

27. Rothwell PM, Wilson M, Elwin CE, et al. Long-term effect of aspirin on colorectal cancer incidence and mortality: 20-year follow-up of five randomised trials. Lancet. 2010;376(9754):1741-1750.

28. Goodman GE, Thornquist MD, Balmes J, et al. The Beta-Carotene and Retinol Efficacy Trial: incidence of lung cancer and cardiovascular disease mortality during 6-year follow-up after stopping beta-carotene and retinol supplements. J Natl Cancer Inst. 2004;96(23):1743-1750.

29. Ebbing M, Bønaa KH, Nygård $\mathrm{O}$, et al. Cancer incidence and mortality after treatment with folic acid and vitamin B12. JAMA. 2009;302(19):2119-2126.

30. Cook NR, Lee IM, Zhang SM, Moorthy MV, Buring JE. Alternate-day, low-dose aspirin and cancer risk: long-term observational follow-up of a randomized trial. Ann Intern Med. 2013;159(2):77-85.

31. Cauley JA, Chlebowski RT, Wactawski-Wende J, et al. Calcium plus vitamin D supplementation and health outcomes five years after active intervention ended: the Women's Health Initiative. J Womens Health. 2013;22(11):915-929.

32. Gao QY, Chen HM, Chen YX, et al. Folic acid prevents the initial occurrence of sporadic colorectal adenoma in Chinese older than 50 years of age: a randomized clinical trial. Cancer Prev Res. 2013;6(7):744-752.

33. Levin B, Lieberman DA, Mcfarland B, et al. Screening and surveillance for the early detection of colorectal cancer and adenomatous polyps, 2008: a joint guideline from the American Cancer Society, the US Multi-Society Task Force on Colorectal Cancer, and the American College of Radiology. CA Cancer J Clin. 2008;58(3):130-160. 
34. Chubak J, Whitlock EP, Williams SB, et al. Aspirin for the Prevention of Cancer Incidence and Mortality: Systematic Evidence Reviews for the U.S. Preventive Services Task Force. Ann Intern Med. 2016;164(12):814-825.

35. Bibbins-Domingo K. Aspirin Use for the Primary Prevention of Cardiovascular Disease and Colorectal Cancer: U.S. Preventive Services Task Force Recommendation StatementAspirin Use for the Primary Prevention of CVD and CRC. Ann Intern Med. 2016;164(12):836-845.

36. Dubé C, Rostom A, Lewin G, et al. The use of aspirin for primary prevention of colorectal cancer: a systematic review prepared for the U.S. Preventive Services Task Force. Ann Intern Med. 2007;146(5):365-375.

37. Cooper K, Squires H, Carroll C, et al. Chemoprevention of colorectal cancer: systematic review and economic evaluation. Health Technol Assess. 2010;14(32):1-206.

38. Carroll C, Cooper K, Papaioannou D, Hind D, Pilgrim H, Tappenden P. Supplemental calcium in the chemoprevention of colorectal cancer: a systematic review and meta-analysis. Clin Ther. 2010;32(5):789-803.

39. Bjelakovic G, Nagorni A, Nikolova D, Simonetti RG, Bjelakovic M, Gluud C. Meta-analysis: antioxidant supplements for primary and secondary prevention of colorectal adenoma. Aliment Pharmacol Ther. 2006;24(2):281-291.

40. Qin T, du M, du H, Shu Y, Wang M, Zhu L. Folic acid supplements and colorectal cancer risk: meta-analysis of randomized controlled trials. Sci Rep. 2015;5:12044.

41. Veettil SK, Saokaew S, Lim KG, Ching SM, Phisalprapa P, Chaiyakunapruk N. Comparative effectiveness of chemopreventive interventions for colorectal cancer: protocol for a systematic review and network meta-analysis of randomised controlled trials. J Gastrointest Oncol. 2016;7(4):595-602.

42. Hutton B, Salanti G, Caldwell DM, et al. The PRISMA extension statement for reporting of systematic reviews incorporating network meta-analyses of health care interventions: checklist and explanations. Ann Intern Med. 2015;162(11):777-784.

43. Higgins JPT, Green S. Cochrane Handbook for Systematic Reviews of Interventions Version 5.1.0 [Updated March 2011].The Cochrane Collaboration; 2011. Available from: http://handbook.cochrane.org/.

44. Higgins JPT. A revised tool for assessing risk of bias in randomized trials. Cochrane Database of Systematic Reviews. 2016;10(Suppl 1).

45. Puhan MA, Schünemann HJ, Murad MH, et al. A GRADE Working Group approach for rating the quality of treatment effect estimates from network meta-analysis. BMJ. 2014;349:g5630.

46. Hoaglin DC, Hawkins N, Jansen JP, et al. Conducting indirect-treatmentcomparison and network-meta-analysis studies: report of the ISPOR Task Force on Indirect Treatment Comparisons Good Research Practices: part 2. Value Health. 2011;14(4):429-437.

47. Caldwell DM, Ades AE, Higgins JP. Simultaneous comparison of multiple treatments: combining direct and indirect evidence. $B M J$. 2005;331(7521):897-900.

48. Chaimani A, Higgins JP, Mavridis D, Spyridonos P, Salanti G. Graphical tools for network meta-analysis in STATA. PLoS One. 2013;8(10):e76654.

49. Guirguis-Blake JM, Evans CV, Senger CA, O'Connor EA, Whitlock EP. Aspirin for the Primary Prevention of Cardiovascular Events: A Systematic Evidence Review for the U.S. Preventive Services Task Force. Ann Intern Med. 2016;164(12):804-813.

50. Dehmer SP, Maciosek MV, Flottemesch TJ, Lafrance AB, Whitlock EP. Aspirin for the Primary Prevention of Cardiovascular Disease and Colorectal Cancer: A Decision Analysis for the U.S. Preventive Services Task Force. Ann Intern Med. 2016;164(12):777-786.

51. Whitlock EP, Burda BU, Williams SB, Guirguis-Blake JM, Evans CV. Bleeding Risks With Aspirin Use for Primary Prevention in Adults: A Systematic Review for the U.S. Preventive Services Task Force. Ann Intern Med. 2016;164(12):826-835.

52. Whitlock EP, Williams SB, Burda BU, Feightner A, Beil T. Aspirin Use in Adults: Cancer, All-Cause Mortality, and Harms: A Systematic Evidence Review for the U.S. Preventive Services Task Force. Rockville (MD): Agency for Healthcare Research and Quality (US); 2015. Available from: http://www.ncbi.nlm.nih.gov/books/NBK321643/. Accessed December 14, 2016.
53. Chatterjee S, Chakraborty A, Weinberg I, et al. Thrombolysis for pulmonary embolism and risk of all-cause mortality, major bleeding, and intracranial hemorrhage: a meta-analysis. JAMA. 2014;311(23): 2414-2421.

54. Jinatongthai P, Kongwatcharapong J, Foo CY, et al. Comparative efficacy and safety of reperfusion therapy with fibrinolytic agents in patients with ST-segment elevation myocardial infarction: a systematic review and network meta-analysis. Lancet. 2017;390(10096): 747-759.

55. Nyaga VN, Arbyn M, Aerts M. Metaprop: a Stata command to perform meta-analysis of binomial data. Arch Public Health. 2014;72(1):39.

56. Efron B, Tibshirani R. An Introduction to the Bootstrap. Boca Raton, FL: Chapman \& Hall/CRC; 1993

57. Singer DE, Chang Y, Fang MC, et al. The net clinical benefit of warfarin anticoagulation in atrial fibrillation. Ann Intern Med. 2009;151(5):297-305.

58. Harris RP, Helfand M, Woolf SH, et al. Current methods of the US Preventive Services Task Force: a review of the process. Am J Prev Med. 2001;20(3 Suppl):21-35.

59. Stürmer T, Glynn RJ, Lee IM, Manson JE, Buring JE, Hennekens CH. Aspirin use and colorectal cancer: post-trial follow-up data from the Physicians' Health Study. Ann Intern Med. 1998;128(9):713-720.

60. Bønaa KH, Njølstad I, Ueland PM, et al. Homocysteine lowering and cardiovascular events after acute myocardial infarction. $N$ Engl $J$ Med. 2006;354(15):1578-1588.

61. Ebbing M, Bleie Ø, Ueland PM, et al. Mortality and cardiovascular events in patients treated with homocysteine-lowering B vitamins after coronary angiography: a randomized controlled trial. JAMA. 2008;300(7):795-804.

62. Thrombosis prevention trial: randomised trial of low-intensity oral anticoagulation with warfarin and low-dose aspirin in the primary prevention of ischaemic heart disease in men at increased risk. The Medical Research Council's General Practice Research Framework. Lancet. 1998;351(9098):233-241.

63. Group TSC. Swedish Aspirin Low-Dose Trial (SALT) of $75 \mathrm{mg}$ aspirin as secondary prophylaxis after cerebrovascular ischaemic events. The SALT Collaborative Group. Lancet. 1991;338(8779):1345-1349.

64. Dutch TIA Trial Study Group, van Gijn J, Algra A, Kappelle J, Koudstaal PJ, van Latum A. A comparison of two doses of aspirin ( $30 \mathrm{mg}$ vs. 283 $\mathrm{mg}$ a day) in patients after a transient ischemic attack or minor ischemic stroke. N Engl J Med. 1991;325(18):1261-1266.

65. Gaziano JM, Sesso HD, Christen WG, et al. Multivitamins in the prevention of cancer in men: the Physicians' Health Study II randomized controlled trial. JAMA. 2012;308(18):1871-1880.

66. Goodman M, Bostick RM, Kucuk O, Jones DP. Clinical trials of antioxidants as cancer prevention agents: past, present, and future. Free Radic Biol Med. 2011;51(5):1068-1084.

67. Park SY, Murphy SP, Wilkens LR, Nomura AM, Henderson BE, Kolonel LN. Calcium and vitamin D intake and risk of colorectal cancer: the Multiethnic Cohort Study. Am J Epidemiol. 2007;165(7):784-793.

68. Li M, Chen P, Li J, Chu R, Xie D, Wang H. Review: the impacts of circulating 25-hydroxyvitamin D levels on cancer patient outcomes: a systematic review and meta-analysis. $J$ Clin Endocrinol Metab. 2014;99(7):2327-2336.

69. Veettil SK, Ching SM, Lim KG, Saokaew S, Phisalprapa P, Chaiyakunapruk N. Effects of calcium on the incidence of recurrent colorectal adenomas: A systematic review with meta-analysis and trial sequential analysis of randomized controlled trials. Medicine. 2017;96(32): e7661.

70. Ng K, Nimeiri HS, Mccleary NJ, et al. SUNSHINE: Randomized double-blind phase II trial of vitamin D supplementation in patients with previously untreated metastatic colorectal cancer. J Clin Oncol. 2017;35(15_suppl):3506-3506.

71. Veettil SK, Teerawattanapong N, Ching SM, et al. Effects of chemopreventive agents on the incidence of recurrent colorectal adenomas: a systematic review with network meta-analysis of randomized controlled trials. Onco Targets Ther. 2017;10:2689-2700. 
72. Wien TN, Pike E, Wisløff T, Staff A, Smeland S, Klemp M. Cancer risk with folic acid supplements: a systematic review and meta-analysis. BMJ Open. 2012;2(1):e000653.

73. Koren G. Folic acid and colorectal cancer: unwarranted fears. Can Fam Physician. 2011;57(8):889-890.

74. Qin X, Shen L, Zhang R, et al. Effect of folic acid supplementation on cancer risk among adults with hypertension in China: A randomized clinical trial. Int J Cancer. 2017;141(4):837-847.
75. Chan AT, Ladabaum U. Where Do We Stand With Aspirin for the Prevention of Colorectal Cancer? The USPSTF Recommendations. Gastroenterology. 2016;150(1):14-18.

76. Serebruany VL, Steinhubl SR, Berger PB, et al. Analysis of risk of bleeding complications after different doses of aspirin in 192,036 patients enrolled in 31 randomized controlled trials. Am J Cardiol. 2005;95(10):1218-1222.
Clinical Epidemiology

\section{Publish your work in this journal}

Clinical Epidemiology is an international, peer-reviewed, open access, online journal focusing on disease and drug epidemiology, identification of risk factors and screening procedures to develop optimal preventative initiatives and programs. Specific topics include: diagnosis, prognosis, treatment, screening, prevention, risk factor modification,

Submit your manuscript here: https://www.dovepress.com/clinical-epidemiology-journal

\section{Dovepress}

systematic reviews, risk and safety of medical interventions, epidemiology and biostatistical methods, and evaluation of guidelines, translational medicine, health policies and economic evaluations. The manuscript management system is completely online and includes a very quick and fair peer-review system, which is all easy to use. 